\title{
Numerical study of wave attenuation by mass of rising bubbles
}

\author{
Mojtaba Shegeft, Madjid Ghodsi Hassanabad, Mojtaba Ezam \\ Department of Marine Science and Technology, Tehran Science and Research Branch, Islamic Azad University \\ Tehran, Iran \\ Mojtaba.shegeft@gmail.com; M.ghodsi@srbiau.ac.ir; m.ezam@srbiau.ac.ir
}

\begin{abstract}
This paper describes a numerical study on the performance of the air bubble breakwater to attenuating wave energy using 2D CFD modelling. This numerical study gives reasonable results which illustrate CFD modelling is one of the best ways to have a good prediction of wave attenuation. Pneumatic breakwater is installed under the sea level, so it is hidden and it does not have a negative impact on shipping. Regarding the advantages of the breakwater and its good compatibility with environment and its high performance as a mobile breakwater, further study in this field is necessary. In the model, Finite volume method has been used to analyse air bubble breakwater, the continuity and momentum equations were selected as the governing equations. Shear Stress Transport (SST) k-omega turbulence model is implemented to the Reynolds Stresses in RANS equations due to the high amount of turbulence in this system. Also, interaction between water and air was analysed with the Volume of Fraction (VOF) method. Finally, according to the numerical models, the Wave attenuation depends on the wavelength and the air discharges from the orifices and there is a positive correlation between the mass of rising bubbles and wave attenuation with constant steepness. Besides, the experimental results and the numerical results of this research were in good accordance. Therefore, it can be concluded that the present numerical method is convenient for pneumatic breakwater modelling.
\end{abstract}

Keywords: Pneumatic breakwater, Wave attenuation, Air bubble, CFD modelling.

\section{Introduction}

Coastal infrastructures require special attention due to their high exposure to weather and wave conditions and their location across the sea. These installations are of great importance to economic and social development, and provide the fundamental infrastructure for foreign trade and internal market exchanges. It is essential that coastal infrastructures have rigorous and precise monitoring, using the appropriate tools and procedures for loss control and, where possible, to predict any inherent risks to these types of structure in order to schedule interventions and provide more efficient maintenance procedures.

Wave energy can be attenuated by mass of rising air bubbles. The pneumatic breakwater can be used instead of some structures which are able to reflect or absorb wave energy [1]. The fact that these types of breakwaters have some advantages that cannot be seen in others should be seriously taken into account. The breakwater does not need so much space and it does not have negative effects on shipping. This device is installed under the sea level. Hence, it is hidden [2]. It can be used in offshore zones to decrease the wave negative impacts on offshore structures, for example, during offshore platforms installations or near shore zones. Due to the advantages of the breakwater and its good compatibility with environment and its high performance as a movable breakwater, and the lack of fully understanding the pneumatic breakwater device, further studies are needed either experimentally, numerically, or a combination of these methods.

Phillip Brasher was the first one who introduced a method for attenuating wave energy by forcing compressed air through a submerged perforated pipe in 1907 [3], then many laboratory studies were performed from 1930 to 1955 . One of the most significant advances during this period was the development by Taylor [4]. In 1949, Schiff, L.I, conducted some laboratory research in the hydrodynamic laboratories in California Institute of technology, he considered one aspect of the effectiveness of a single or repeated air bubble screen as a breakwater for gravitational waves in shallow water [5]. Carr investigated mobile breakwater, including some tests with pneumatic breakwater. He concluded that the power requirements were excessively large, in 1950 [6]. In 1955, both pneumatic and hydraulic breakwater were studied by Evans. He presented the data on the surface-current velocities required to attenuate waves of different lengths and provided a general indication of the horsepower requirements [7]. In 1955, Wetzel prepared a report on the results of preliminary small-scale tests and the Comparisons of the results were made with Taylor's theory and some of Carr's experimental results [8]. In 2011, Beynet [9] 
presented a paper about securing passenger transfer between a cruise ship and a tender, using pneumatic breakwater ,Then in 2015, Mr Beynet [10] presented an innovative mechanism designed to attenuate the formation of bow waves thanks to a pneumatic breakwater system (bubbles injection) embedded on boats and barges. In 2017, the Eigenfunctionexpansion technique was derived by Paprota and Sulisz [11] to give reasonable conclusions in a certain range of conditions. The experimental study on wave-current structure around a pneumatic breakwater was presented by Paprota [12]. So far many laboratory studies have been done. However, there aren't enough numerical studies in this field. In this research, wave attenuation by mass of rising bubbles in different wave lengths is studied numerically.

\section{Boundary Condition and mesh design}

In the numerical model (fig.1), the wave tank dimensions and the wave parameters and the air discharge are the same as the experimental case which have been done by Lorenz G. and his colleagues [13]. The top (AD) opening of the tank was modelled as a pressure inlet boundary, with the pressure set to a gauge pressure of zero. The bottom (BC) was modelled as a no-slip wall. The inlet, $(\mathrm{AB})$ or Flap type wave generator, was a velocity inlet that made use of the open cannel wave boundary function in fluent. This function works similarly to the open channel function. The boundary (DC) was modelled as pressure outlet that made use of open channel boundary function. There is a danger with using this function because it involves some wave reflections which are higher than the fixed fluid surface. Therefore to reduce the unwanted reflected waves from outlet boundary, the numerical beach function is used in the model. This function allows for damping of incoming waves which was found to work effectively to eliminate the reflections completely.

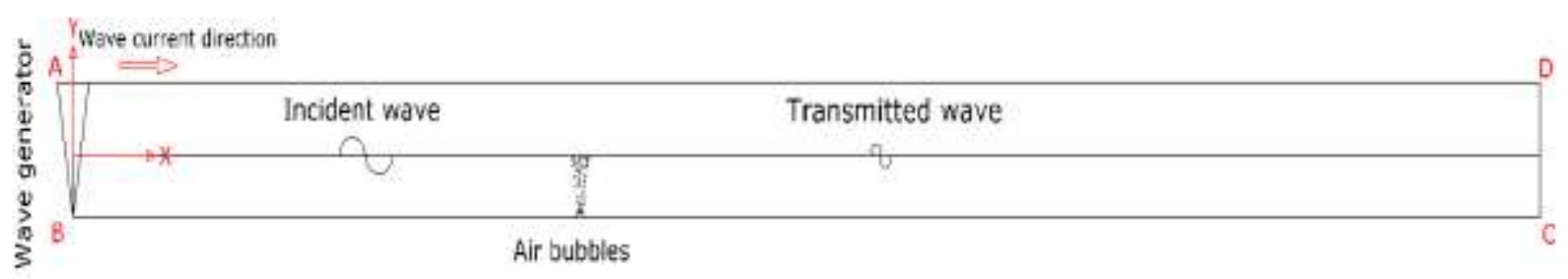

Fig. 1: The sketch of the numerical model of air bubble breakwater.

Mesh designing is so important to get good results from the model. The quality of the conclusions depends on the mesh and time step size. Quadrilateral elements are used in the model. Due to improving the quality of the mesh design and reducing the time steps, mesh dimensions were changed near the orifice. Finally, two models have been investigated. The total cells count 240600 (Mesh1), and 150500 (Mesh2), and their details can be seen from the table 1. Because of the fact that there was no difference in the results of two models and the number of cells in the second model was much less than first one, the second model is used in this project.

Table 1: The mesh details.

\begin{tabular}{|c|c|c|c|}
\hline Cells & Faces & Nodes & 2D models \\
\hline 240600 & 483706 & 243107 & 1 \\
\hline 150500 & 302605 & 152106 & 2 \\
\hline
\end{tabular}

\section{Governing equations}

The sketch of the pneumatic breakwater can be seen in Fig.1. It is assumed that the fluid is incompressible. A righthand Cartesian coordinate system is selected in which $\mathrm{x}$ axis is horizontal and $\mathrm{y}$ axis is vertically upward. The direction of the wave current is left to right.

The VOF model can model two or more immiscible fluids by solving a single set of momentum equations and tracking 
the volume fraction of each of the fluids throughout the domain for the $\mathrm{q}^{\text {th }}$ phase, this equation has the following form:

$$
\begin{gathered}
\frac{1}{\rho_{\mathrm{q}}}\left[\frac{\partial}{\partial_{\mathrm{t}}}\left(\mathrm{a}_{\mathrm{q}} \rho_{\mathrm{q}}\right)+\nabla \cdot\left(\mathrm{a}_{\mathrm{q}} \rho_{\mathrm{q}} \overrightarrow{\mathrm{v}_{\mathrm{q}}}\right)=\mathrm{S}_{\mathrm{a}_{\mathrm{q}}}+\sum_{\mathrm{p}=1}^{\mathrm{n}}\left(\mathrm{m}_{\mathrm{pq}}^{\cdot}-\mathrm{m}_{\mathrm{qp}}^{\cdot}\right)\right] \\
\sum_{\mathrm{q}=1}^{\mathrm{n}} \mathrm{a}_{\mathrm{q}}=1
\end{gathered}
$$

Where $\mathrm{m}_{\mathrm{qp}}$ the mass transfer from phase $\mathrm{q}$ to phase $\mathrm{p}$ is, $\mathrm{m}_{\mathrm{pq}}$ is the mass transfer from phase $\mathrm{p}$ to phase $\mathrm{q}$. The source term $\mathrm{S}_{\mathrm{a}_{\mathrm{q}}}$ is zero.

In the single fluid model, the phase function $\mathrm{a}_{\mathrm{q}}$ is equal to 1 in water and 0 in air. The interface is defined by $\mathrm{a}_{\mathrm{q}}=0.5$. The magnitude of the physical characteristics of the fluids depends on the local phase. They are defined as:

$$
\begin{aligned}
& \rho=\rho_{1} \text { And } \mu=\mu_{1} \text { if } \mathrm{a}_{\mathrm{q}} \geq 0.5 \\
& \rho=\rho_{0} \text { And } \mu=\mu_{0} \text { if } \mathrm{a}_{\mathrm{q}}<0.5
\end{aligned}
$$

Where $\rho_{0}, \rho_{1}, \mu_{0}$ and $\mu_{1}$ are the densities and viscosities of fluid 0 and 1 , respectively [14].

The mixture of air and water is considered as a fluid of variable density. The dynamic viscosity coefficient of the fluid are defined as:

$$
\begin{aligned}
& \rho=\alpha_{0} \rho_{0}+\alpha_{1} \rho_{1} \\
& \mu=\alpha_{0} \mu_{0}+\alpha_{1} \mu_{1}
\end{aligned}
$$

Where $\alpha_{0}$ and $\alpha_{1}$ are volume fractions of air and water respectively.

The advanced turbulence model is based on Reynolds averages of the governing equations. In Reynolds averaging, the solution variables in the instantaneous Navier-Stokes equations are decomposed into the mean and fluctuating components. Substituting expressions of this form for the flow variables into the instantaneous continuity and momentum equations and taking a time (or ensemble) average yields the ensemble-averaged momentum equations. They can be written in Cartesian tensor form as:

$$
\begin{gathered}
\frac{\partial \rho}{\partial t}+\frac{\partial}{\partial x_{i}}\left(\rho u_{i}\right)=0 \\
\frac{\partial}{\partial t}\left(\rho u_{i}\right)+\frac{\partial}{\partial x_{j}}\left(\rho u_{i} u_{j}\right)=-\frac{\partial p}{\partial x_{i}}+\frac{\partial}{\partial x_{j}}\left[\mu\left(\frac{\partial u_{i}}{\partial x_{j}}+\frac{\partial u_{j}}{\partial x_{i}}-\frac{2}{3} \delta_{i j} \frac{\partial u_{l}}{\partial x_{l}}\right)\right]+\frac{\partial}{\partial x_{j}}\left(-\rho \overline{u_{1}^{\prime}} \overline{u_{j}^{\prime}}\right)
\end{gathered}
$$

The equations (5) and (6) are called "Reynolds-averaged" Navier-Stokes (RANS) equations. According to equation (6) "Reynolds stresses" $\left(-\rho \overline{u_{1}^{\prime}} \overline{u_{j}^{\prime}}\right)$ represents the effects of turbulence.

Features of the Shear-Stress Transport (SST) K omega model were more accurate and reliable for this numerical model.

$$
\frac{\partial}{\partial_{\mathrm{t}}}(\rho \mathrm{k})+\frac{\partial}{\partial \mathrm{x}_{\mathrm{i}}}\left(\rho \mathrm{ku}_{\mathrm{i}}\right)=\frac{\partial}{\partial \mathrm{x}_{\mathrm{j}}}\left(\Gamma_{\mathrm{k}} \frac{\partial \mathrm{k}}{\partial \mathrm{x}_{\mathrm{j}}}\right)+\mathrm{G}_{\mathrm{k}}-\mathrm{Y}_{\mathrm{k}}+\mathrm{S}_{\mathrm{k}}
$$




$$
\frac{\partial}{\partial_{\mathrm{t}}}(\rho \omega)+\frac{\partial}{\partial \mathrm{x}_{\mathrm{j}}}\left(\rho \omega \mathrm{u}_{\mathrm{i}}\right)=\frac{\partial}{\partial \mathrm{x}_{\mathrm{j}}}\left(\Gamma_{\omega} \frac{\partial \omega}{\partial \mathrm{x}_{\mathrm{j}}}\right)+\mathrm{G}_{\omega}-\mathrm{Y}_{\omega}+\mathrm{D}_{\omega}+\mathrm{S}_{\omega}
$$

Where the term $G_{k}$ represents the production of turbulence kinetic energy. $G_{\omega}$ represents the generation of $\omega . \Gamma_{k}$ and $\Gamma_{\omega}$ indicate the effective diffusivity of $\mathrm{k}$ and $\omega$, respectively. $\mathrm{Y}_{\mathrm{k}}$ and $\mathrm{Y}_{\omega}$ indicate the dissipation of $\mathrm{k}$ and $\omega$ due to turbulence. $D_{\omega}$ represents the cross-diffusion term. $S_{k}$ and $S_{\omega}$ are user-defined source terms $[15,16]$

\section{Numerical simulation}

To create a free surface in the CFD programs, the domain must somehow be divided into two phases of a fluid. Fluent can model the effects of open-channel flow using a Volume of Fluid (VOF) formulation. Because of the amount of turbulence in this system the Shear Stress Transport (SST) k-omega turbulence model is implemented to the Reynolds Stresses in RANS equations. The materials and their properties used for this are fairly simple. Only two fluids were necessary for this project, water in liquid form, and air, their materials and properties can be seen from the table 2 .

Table 2: The materials properties.

\begin{tabular}{|l|ll|}
\hline Air density & 1.225 & $\frac{\mathrm{Kg}}{\mathrm{m}^{3}}$ \\
\hline Air viscosity & $1.7894 * 10^{-5}$ & $\frac{\mathrm{Kg}}{\mathrm{m} \cdot \mathrm{s}}$ \\
\hline Water density & 998.2 & $\frac{\mathrm{Kg}}{\mathrm{m}^{3}}$ \\
\hline Water viscosity & 0.001003 & $\frac{\mathrm{Kg}}{\mathrm{m} \cdot \mathrm{s}}$ \\
\hline
\end{tabular}

This type of breakwater consists of a perforated pipe, usually on the sea bed, through which compressed air is pushed upward through the orifices on the pipe. As the air bubbles rise, they move and drag water particles in an upward motion. When this mixture reaches the surface, the air escapes, while the flow of water branches into two horizontal currents, the turbulence generated by the system produces some attenuation of the waves. In order to get the best results, the orifice axis should be perpendicular to the direction of the wave's current [17]. The velocity vectors and their directions which have been produced by mass of rising bubble can be seen in the (fig.2-3).

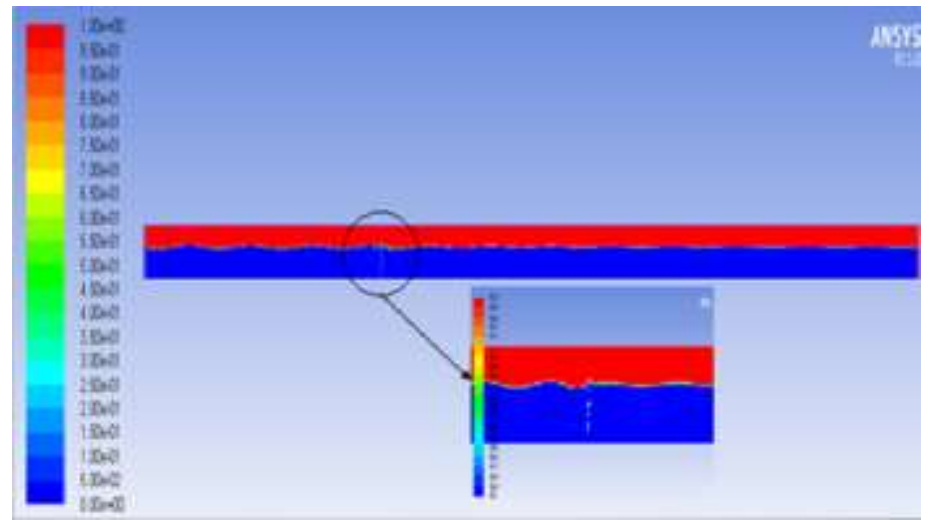

Fig. 2: Wave attenuation, numerical study.

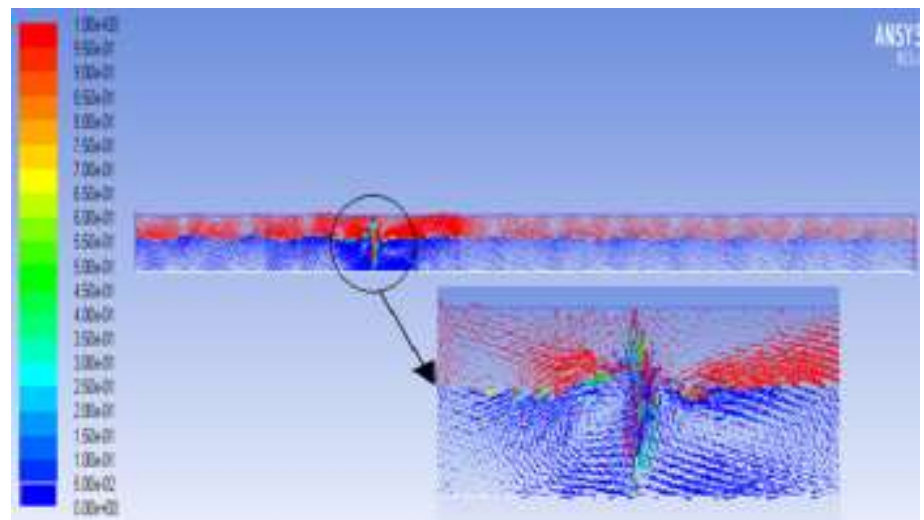

Fig. 3: The pattern of velocity vector.

The numerical results in this model are validated against experimental studies which have been done by Lorenz G. and his colleagues in St. Anthony Falls hydraulic laboratory. The geometry of numerical model, the wave parameters 
and the air discharge are the same as the experimental case. According to the sketch of the laboratory study, The Depth of channel is $0.365(\mathrm{~m})$ and the width of channel is $0.601(\mathrm{~m})$, the depth of water $(\mathrm{h})$ is $0.304 \mathrm{~m}$, orifice diameter is $1 \mathrm{~mm}$, distance between the orifice axis and wave generator is $3.65(\mathrm{~m})$ and the distance between measured attenuation and the orifice axis is $4.26(\mathrm{~m})$. The number of orifice during the laboratory study was $23 \mathrm{per} \mathrm{ft}$, so the amount of air discharged from an orifice is calculated and is used in numerical study. The wavelengths $(\mathrm{L})$ are $0.9,0.74,0.85(\mathrm{~m})$ and the wave steepness is 0.04 during numerical simulation.

Wave attenuation is calculated by equation $\left(1-\frac{\mathrm{H}_{\mathrm{T}}}{\mathrm{H}_{\mathrm{I}}}\right)$ which was expressed in laboratory study. In this equation the transmitted wave height is defined as $\left(\mathrm{H}_{\mathrm{T}}\right)$ and the incident wave height is defined as $\left(\mathrm{H}_{\mathrm{I}}\right)$. Figure 5 shows the wave attenuation and white colors show the wave surface and air bubbles.

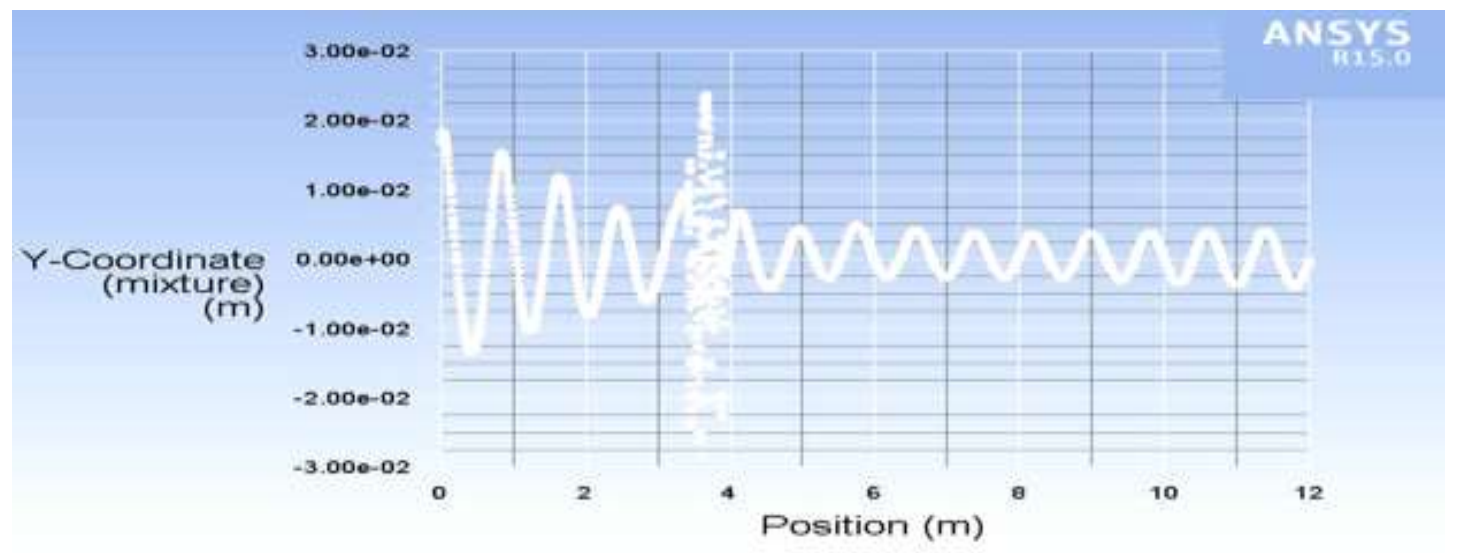

Fig. 5: Wave attenuation for wave length $0.8 \mathrm{~m}$.

Figure 6 and 7 shows the comparison of attenuation between experimental and numerical results. The comparisons exhibit the good agreements between the numerical and the experimental results. By calculating the accuracy of the results the average of the percent error for fig. 6 and fig. 7 are $4.37 \%$ and $4.18 \%$, respectively which are below of 5\%. As the graphs show, the amount of wave attenuation increased dramatically because of the amount of air discharged from the orifice. The constant wave steepness 0.04 is used to validation of the numerical models, with different incident wavelength $0.74 \mathrm{~m}$ and $0.95 \mathrm{~m}$.

Table 3: the results of numerical simulation (wave length $0.74 \mathrm{~m}$ ).

\begin{tabular}{|l|l|l|l|}
\hline $\begin{array}{c}\text { Unit } \\
\text { Discharge in } \\
\left(\mathbf{m}^{\mathbf{3} / \text { s.m }} \text { ) free air }\right.\end{array}$ & $\begin{array}{l}\text { Wave } \\
\text { Steepness }\end{array}$ & $\begin{array}{l}\text { Wave } \\
\text { length }(\mathbf{m})\end{array}$ & attenuation \\
\hline 0.001132 & 0.04 & 0.74 & 0.66 \\
\hline 0.000906 & 0.04 & 0.74 & 0.59 \\
\hline 0.000708 & 0.04 & 0.74 & 0.53 \\
\hline 0.000425 & 0.04 & 0.74 & 0.32 \\
\hline
\end{tabular}




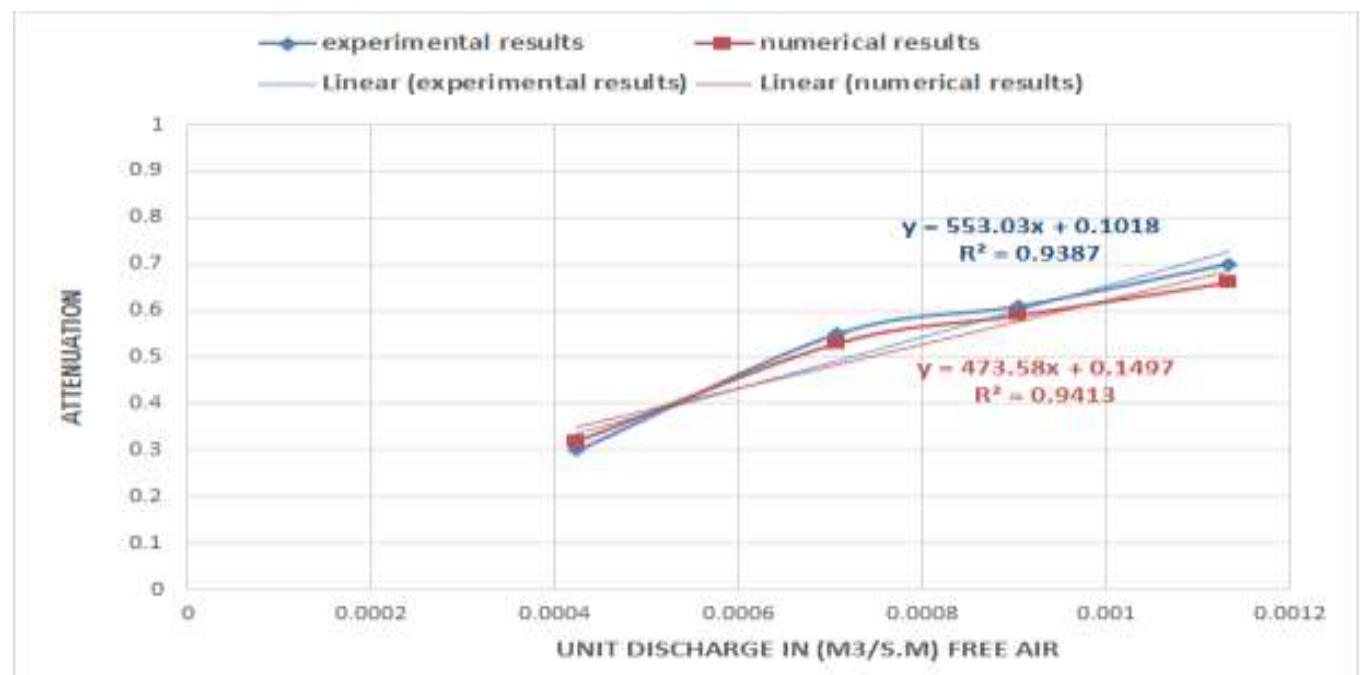

Fig. 6: The comparison of wave attenuation between experimental and numerical simulation (Wave length $0.74 \mathrm{~m}$ ).

Table 4: The results of numerical simulation (wave length $0.95 \mathrm{~m}$ ).

\begin{tabular}{|l|l|l|l|}
\hline $\begin{array}{c}\text { Unit } \\
\text { Discharge in } \\
\left(\mathbf{m}^{\mathbf{3}} / \mathbf{s . m}\right) \text { free air }\end{array}$ & $\begin{array}{l}\text { Wave } \\
\text { Steepness }\end{array}$ & $\begin{array}{l}\text { Wave } \\
\text { length (m) }\end{array}$ & attenuation \\
\hline 0.00283 & 0.04 & 0.95 & 0.58 \\
\hline 0.00184 & 0.04 & 0.95 & 0.49 \\
\hline 0.000849 & 0.04 & 0.95 & 0.25 \\
\hline 0.000509 & 0.04 & 0.95 & 0.098 \\
\hline
\end{tabular}

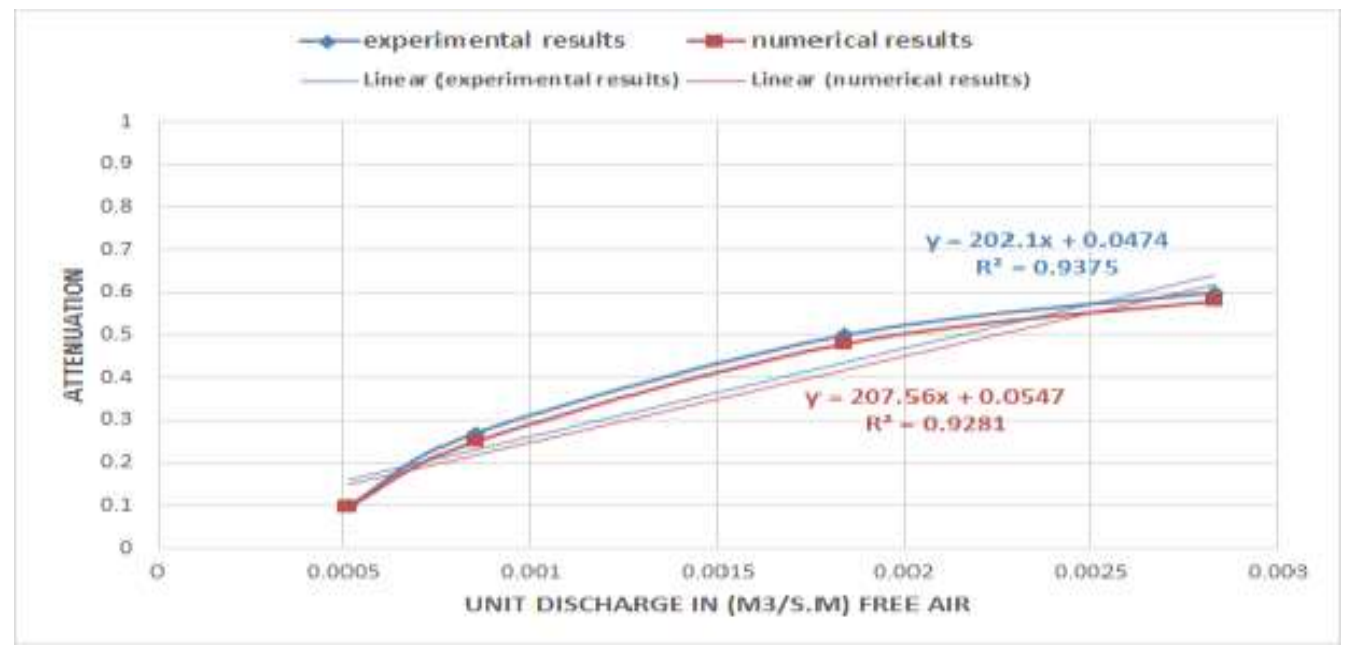

Fig. 7: The comparison of wave attenuation between experimental and numerical simulation (Wave length $0.95 \mathrm{~m}$ ). 
Table 5: The results of numerical simulation (wave length $0.8 \mathrm{~m}$ ).

\begin{tabular}{|l|l|l|l|}
\hline $\begin{array}{c}\text { Unit } \\
\text { Discharge in } \\
\left(\mathbf{m}^{\mathbf{3}} / \mathbf{s} . \mathbf{m}\right) \text { free air }\end{array}$ & $\begin{array}{l}\text { Wave } \\
\text { Steepness }\end{array}$ & $\begin{array}{l}\text { Wave } \\
\text { length }(\mathbf{m})\end{array}$ & attenuation \\
\hline 0.00283 & 0.04 & 0.8 & 0.81 \\
\hline 0.00184 & 0.04 & 0.8 & 0.72 \\
\hline 0.000849 & 0.04 & 0.8 & 0.59 \\
\hline 0.000509 & 0.04 & 0.8 & 0.31 \\
\hline
\end{tabular}

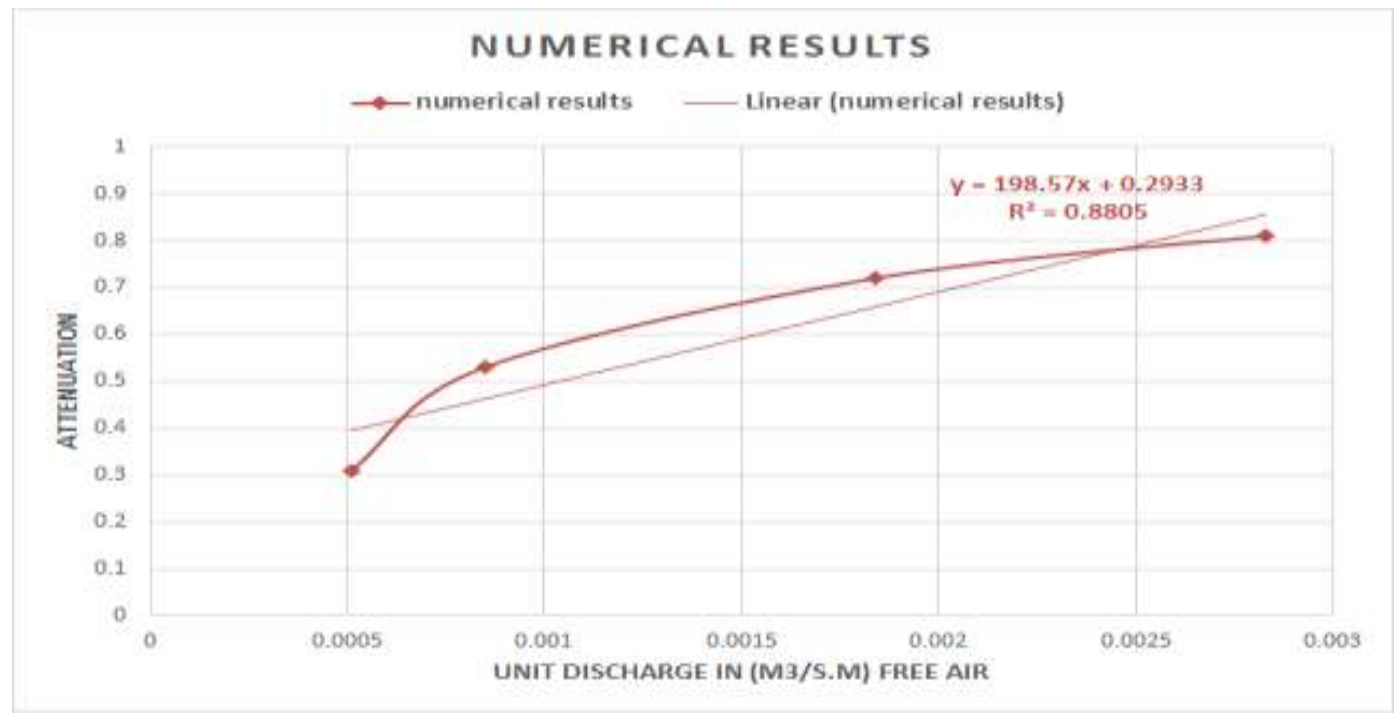

Fig. 8: The numerical simulation results of wave attenuation (Wave length $0.8 \mathrm{~m}$ ).

\section{Conclusion}

2D CFD model is implemented in this paper. The effects of mass of rising bubbles on attenuating waves with different wave lengths was study numerically. The depth of water is $0.304 \mathrm{~m}$, the wave lengths are $0.9,0.74,0.85 \mathrm{~m}$ 'and the wave steepness is 0.04 . The model is validated in good agreement against the experimental study. From the results of present study, the following conclusions are drawn:

- According to numerical models, the Wave attenuation depends on the wavelength and the air discharges from the orifices.

- As a result, with constant steepness, if wave length is increased, air bubbles discharge should be increased to achieve the same wave attenuation.

- The results illustrate that the horizontal currents produced by the mass of rising bubbles is so important for attenuating wave energy and there is a positive correlation between these currents and air bubble discharge from the orifices. When air bubble discharge is increased, the horizontal currents produced by the mass of rising bubbles will increase.

- According to the equations which presented in the figures $6,7,8$ we can make good predictions about wave attenuating by air discharges from the orifices. 
- It can be concluded that the present numerical method is convenient for air bubble breakwater modelling and it can be used instead of expensive experimental studies.

- To reduce the energy required to produce air bubbles and decrease the amount of air bubbles in deep water, Pneumatic breakwaters can be used with other types of breakwaters such as submerged breakwaters.

- The combination of Pneumatic breakwater and submerged breakwater to increase the performance of Pneumatic breakwaters is highly recommended as an integrated solution in deep waters.

\section{References}

[1] Y. Iwagaki, T. Asano, T. Honda, "Combination Effect of Pneumatic Breakwater and Other Type Breakwater on Wave Damping," in 16th International Conference on Coastal Engineering, Hamburg, Germany, 1978, pp. 2172 - 2190.

[2] P. S. Bulson, "The theory and design of bubble breakwaters," in 11th International Conference on Coastal Engineering, London, United Kingdom, 1968, pp. 995-1015.

[3] P. Brasher, "Pneumatic breakwater: Air bubbles employed to form breakwater," Compressed Air Magazine, vol. 20, pp. 752, 1915.

[4] G. I. Taylor, "The action of a surface current used as a breakwater," J. Proceedings of the Royal Society A: Mathematical, Physical and Engineering Sciences Series, vol. 231, no. 1187, pp. 466-478, 1955.

[5] L. I. Schiff, “Air bubble breakwater," Pasadena, United States: California Institute of Technology, Hydrodynamics Laboratory, Report No. N- 64.1, 1949.

[6] J. H. Carr, "Mobile breakwater studies," Pasadena, United States: California Institute of Technology, Hydrodynamics Laboratory, Laboratory Report No. N-64.2, 1950.

[7] J. T. Evans, "Pneumatic and similar breakwater," Proceedings of the Royal Society of London. Series A, Mathematical and Physical Sciences, vol. 231, no. 1187, pp. 457-466, 1955.

[8] J. M. Wetzel, "Experimental studies of pneumatic and hydraulic breakwaters," Minnesota, USA: St. Anthony Falls Hydraulic Laboratory, University of Minnesota, Proj. Rep. No. 46, 1955.

[9] J. Beynet, "Scuring passenger transfer between cruise-ship and tender," in 7th Maritime Systems and Technology (MAST) Global Conference and Trade-show, Marseille, France, 2011.

[10] J. Beynet, P. Chobert, M. De Vleeschouwer, "Bow wave's mitigation through bubble injection application to river transport to protect the natural banks of inland waterways," Hydrodynamics and simulation applied to inland waterways and port approaches, Paris, France, 2015.

[11] M. Paprota, W. Suliza, "Modelling of wave transmission through a pneumatic breakwater," Journal of Hydrodynamics, Ser. B, vol. 29, no. 2, pp. 283-292, 2017.

[12] M. Paprota, "Experimental study on wave-current structure around a pneumatic breakwater," Journal of Hydroenvironment Research, vol. 17, pp. 8-17, 2017.

[13] L. G. Straub, C. E. Bowers, Z. S. Tarapore, "Experimental studies of pneumatic and hydraulic breakwaters," Minnesota, USA: University of Minnesota, St. Anthony Falls Hydraulic Laboratory, Technical Paper No. 25, Series B, 1959.

[14] P. Lubin, S. Vincent, S. Abadie, J. Caltagirone, "Three-dimensional Large Eddy Simulation of air entrainment under plunging breaking waves," J. Coastal Engineering, vol. 53, no. 8, pp. 631-655, 2006.

[15] D. C. Wilcox, "Turbulence Modeling for CFD," California, USA: DCW Industries, Inc., La Canada, California, 1993.

[16] F. R. Menter, "Two-Equation Eddy-Viscosity Turbulence Models for Engineering Applications," J.AIAA Journal, vol. 32, no. 8, pp. 1598-1605, 1994.

[17] L. Z. Hales, Floating Breakwaters: State of the Art Literature Review," Mississippi, USA: U.S. Army, Corps of engineers, Coastal Engineering Research Center, Waterways Experiment Station, Hydraulics Laboratory Vicksburg, 1982. 